\title{
Research of History Existence and Development of Ancient Architecture
}

\author{
Qian Dong ${ }^{1}$
}

${ }^{1}$ College of Civil and Conservancy Engineering, Ningxia University, Yinchuan, 750021

KEYWORDS: Ancient Architecture; History Existence and Development

\begin{abstract}
Building under the guidance of Chinese ancient culture produced, structures, construction methods and related systems. The scope of Chinese ancient buildings throughout half of Asia and many ethnic minority areas, plays an important role cannot be ignored in the history of world architecture. Oracle, many Chinese characters borrowed architectural image of two top of the hill to coinage, modern Chinese characters in the radical "Baogaitou" is the direct manifestation of the image of the building. With respect to Western civilization, the advantages of wood construction material of Chinese ancient buildings full play to the four corners of a large warped roof and brackets as a symbol; the same time, along the $400 \mathrm{~mm}$ isohyet stretches thousands of kilometers from the Warring States Period began construction of the Great Wall, in the loss of the historical role of defense after the northern nomads, has become a symbol of Chinese civilization, has become a symbol of national spirit.
\end{abstract}

\section{Introduction}

Oriental ancient architecture, ancient architecture in particular China, generally speaking are mainly wooden structures, brick, tile, stone, supplemented develop. Judging from the exterior of the building, each building by, middle, and lower parts, on the roof, next to the base, the middle pillars, doors, windows and walls. Under the column above the eaves brackets interludes, which is represented by the East China Architectural unique member. Both brackets supporting the eaves of the house and the ceiling beams, but also has a strong decorative effect. From the construction categories that Chinese ancient buildings including the palace mansion, defensive architecture, monumental and adorn buildings, tombs and buildings, the garden of the building, worship buildings, bridges and water conservancy construction, residential buildings, recreational buildings, religious buildings, social buildings , commercial buildings, manufacturing buildings, etc., each of which can be subdivided into several sections. Classification, although complicated, but the wooden architecture has been the development of Chinese ancient buildings in the mainstream, that is different from the traditional Chinese architecture reflects the biggest difference where Western architecture. Compared with the West ancient architecture, ancient Chinese architecture preference in the choice of materials wood, it has been for thousands of years, and wooden frame structures based. This structure is the way the columns, beams and purlins along the other major component composed of nodes between each member with a tenon combined to form a flexible framework. This form has been found that a combination of tenon in Yuyao, Zhejiang Hemudu ruins of primitive society building, that it in 7000 years ago, has been formed.

\section{Historical and Cultural Value of Chinese Ancient Architecture}

As a historical and cultural relics, ancient buildings and tourism destined inextricably linked. Even as a city symbol of national history and culture, ancient architecture with multiple values and 
functions, if these values cannot be effectively presented to the public, then the value of ancient buildings will be missing phenomenon. Because of its unique tourism can be a pleasant public function, it will undoubtedly become the primary means of ancient architecture value impressions. Tourism show the form of ancient architecture, able to impart knowledge, enlightened wisdom, cultivate character, but also to promote national culture, the continuation of historical context, evoke patriotism; at the same time, tourism makes the concept of protection of ancient buildings is growing in popularity, and thus stimulate spontaneous or consciously protect the public behavior of ancient buildings. Valuable ancient building, which is in addition to money and sweat piled, more importantly, they are relics of history, I do not know how many years after years of training, some several hundred years, a thousand years of history. If they are destroyed, it is impossible to obtain. For example, a Tang and Song period of ancient buildings were demolished, and can never again have, or be able to restore the vertical According to the information, but it was a replica of a fake antiques, it also greatly reduced the value. So people often put a heritage, the destruction of a historic building known as the "irreparable damage, irreparable loss." Ancient architecture ancient architecture is the main result of the activities, is China's ancient architectural technology, crystallization of the art, but also the carrier of ancient and even modern political, economic and social activities in our country, is a comprehensive reflection of the history of ancient China, social, political, economic, cultural identity heritage, high value, representativeness, wide distribution of time across large, diverse types of features, has become the main target since the work carried out heritage conservation of immovable heritage conservation. Ancient architecture history and culture of the carrier, a special property, in the modernization drive, it has a dual value protection and utilization.

\section{Ancient Architecture Development Research based on Protection Priority}

China's ancient architectural forms, multi-class image, a large number of relics is an important material basis of tourism development, enrich the connotation of China's ancient architecture, artistic conception, different ancient buildings mapped out different mood, can evoke tourists of history memory, get different emotions and ideas to stimulate the association, or passionate generous, majestic solemn, quiet or tranquil, quiet and elegant, or boundless great, magnificent, or small and slender and graceful. Ancient architecture artistic conception entailed so broad and deep, and its way of expression necessarily diverse, given the ancient architecture strange soul, which is China's ancient architecture different from the West notable features, but also reflects China's ancient architecture heterogeneity side. In addition, the presence of more or less ancient architecture differences in its hierarchy, geographical features, history, culture, detail treatment and many other aspects, so that different buildings have different characteristics. E.g. due to different geographical characteristics, southern Anhui style architecture revealing the elegant Jiangnan scenery and tranquil chic, if ink Dan rendered artistic style; northern ancient buildings have a unique sense of dignified simplicity of the north; no mood Western Tibetan ancient architecture Confucianism, Taoism philosophical thought, and no Jiangnan poetic, but showed a Buddhist atmosphere, revealing a mysterious, deep, rough meaning. Another example is strictly controlled by the architectural hierarchy, reflecting a greater sense of difference and ancient buildings in the type system. In order to ensure that the desired social order at the time of the ruling class hope to make it the rule of long-term stability, rulers formulated a set of laws and institutions or legal provisions requiring people to follow the status of the differences in the legal community and political life, and to make sure they can use architectural forms and construction scale Sichuan. All with the emperor related buildings, everyone with its image and to show the general layout and royal style supreme 
imperial power, its next level figures shall be according to their position in society to determine their own building, but cannot be arbitrary. Architectural differences such strict hierarchy of control in many ancient buildings can comprehend the obvious. Special feature is the soul of tourism, ancient buildings lost if differences and stereotyped, lost its attraction and tourism development momentum. As a unique tourism resources, tourism is one of many ancient buildings have to sign a local "tourist card."

\section{Ancient Architecture Protection and Tourism Development Proposals}

The value of ancient buildings mainly in the authenticity and integrity of the load history. Adhere to the "repair the old as" the status quo is to save and restore the status quo ante, to ensure historical information authenticity and integrity. As architect Liang said: "The protection of ancient architecture is going to make it live longer, rather than rejuvenation." UNESCO issued a "code of ethics of ancient building protection", the purpose is to urge people to retain the original style of the ancient buildings. Thus, the "repair old as" to protect the authenticity and integrity are the basic principles of protection of historic buildings, it reflects the history of the space cannot be replaced and regeneration.

In the current protection of ancient buildings, often focusing on the physical form of the protection of ancient architecture, while ignoring the need to protect the surrounding environment coordination area style and atmosphere, which weakened the original style of ancient buildings to a certain extent. Protect the environment and atmosphere of ancient architecture is an extension of the protected object, it will help strengthen the depth and breadth of protection. Contemporary theoretical maximum protection of ancient architecture outlined in "Venice Declaration" clearly states: "The protection of a heritage building, a means appropriate to protect the environment in any place where there is a traditional environment must be protected." China's ancient architecture has experienced thousands of years change, their environment has been highly fused together, inseparable. This melt kneading with nature, in harmony with its texture space, to a certain extent, reflects the traditional Chinese "Heaven" philosophy. Only the common protection of ancient architecture itself and coordinate its environment and atmosphere, will better protect the historical appearance of ancient buildings. As a result of the construction of the Three Gorges and the overall relocation Zhangfei, in strict accordance with the "repair the old as" principle, so that it internal layout and structure of the slightest change did not happen, and the new office environment is substantially similar to the original environment, called China's ancient architecture protection model.

China's ancient building protection funds mainly rely on state investment, but simply relying on government funding, protection of ancient architecture must be very difficult, and therefore raise the funds needed to update the protection of ideas, mobilize social forces and funds, so that the social value of the maximum benefit of the ancient buildings, to achieve a desired situation. General Financing methods are: (1) set up a special foundation to raise funds to protect ancient buildings, extensive funding through donations to absorb market funds. (2) clear legislated retain a certain proportion of funds from tourism revenue, as an important source of funds for protection. (3) through the issuance of bonds or bank loans tourism financing, set aside a certain percentage of funds used for protection of ancient buildings of special funds. Such as 2004 on February 19, Beijing BTG's first foray into the domestic corporate bond market, issuing a total of one billion yuan of tourism bonds, to raise the necessary funds ancient architecture protection and tourism development provides a new way of thinking. Actively broaden protection funding sources at the same time, we should increase the protection of financial supervision, so that limited resources can 
be effectively used for the protection and restoration of ancient buildings, for which "the implementation of Conservation Law" states: Protection of special funds shall relics administrative department, investment department, finance department in charge in accordance with relevant state regulations implemented jointly managed, no unit or individual may occupy, misappropriate. Protection money wise allocation and use, ensuring the protection and restoration of ancient buildings cause benign operation.

Ancient architecture protection is a very complex science, requiring protection professionals should have the buildings, city, history, archeology, art, tourism and other aspects of knowledge, so to form a complete system of protection of professional education, the creation of protected architects, engineers, protection and other training system by highly trained professionals to guide the protection and restoration of ancient buildings. At the same time, but also ancient crafts and traditional mining technology, training familiar with local building techniques and technologies of craftsmen, workers, and the formation of a certain literacy skills

\section{Conclusion}

Affected by China's political, economic, legal and ideological level of the people, the protection of ancient architecture is changing from ancient to modern twists and turns, and now the rapid development of social economy, people's living standards improve and ideology. In this excellent situation if not strengthen efforts to protect ancient buildings, until the splendid architectural heritage disappearance we will regret. So from now on, we must continue to enhance public ancient building protection awareness, to strengthen the ancient buildings to maintain, strengthen professional training, so that protection of ancient architecture and new urban construction in parallel, so that represents our history and culture of the ancient architectural heritage to protect and passed along.

\section{Acknowledgements}

Proj: Acknowledgement by Project of Science and Technology of Ningxia University. Project NO. ZR1224

\section{Reference:}

[1] Xin Huiqin. Old Italian architectural conservation and reuse of transformation [D]. Tianjin: Tianjin University, 2005: 73-76.

[2] Cao Yongkang. Cultural relics in China Theoretical Analysis and Practice of ancient architecture protection research [D]. Control, Zhejiang: Zhejiang University, 2008: 103-105.

[3] Liu Naitao. Chinese philosophy to protect ancient buildings [J]. Heritage Spring, 2008 (6): 43-46. 